\title{
Diversification of U.S. medical schools via affirmative action implementation Shaheen Emmanuel Lakhan*
}

\author{
Address: Faculty of Arts and Sciences, Harvard University, Cambridge, MA, USA \\ Email: Shaheen Emmanuel Lakhan* - slakhan@fas.harvard.edu \\ * Corresponding author
}

Published: 17 September 2003

BMC Medical Education 2003, 3:6
Received: 14 May 2003

Accepted: 17 September 2003

This article is available from: http://www.biomedcentral.com/1472-6920/3/6

(C) 2003 Lakhan; licensee BioMed Central Ltd. This is an Open Access article: verbatim copying and redistribution of this article are permitted in all media for any purpose, provided this notice is preserved along with the article's original URL.

\begin{abstract}
Background: The diversification of medical school student and faculty bodies via race-conscious affirmative action policy is a societal and legal option for the U.S. Supreme Court has recently ruled its use constitutional. This paper investigates the implications of affirmative action, particularly raceconscious compared to race-blind admissions policy; explains how alternative programs are generally impractical; and provides a brief review of the history and legality of affirmative action in the United States.
\end{abstract}

Discussion: Selection based solely on academic qualifications such as GPA and MCAT scores does not achieve racial and ethnic diversity in medical school, nor does it adequately predict success as practicing physicians. However, race-conscious preference yields greater practice in underserved and often minority populations, furthers our biomedical research progression, augments health care for minority patients, and fosters an exceptional medical school environment where students are better able to serve an increasingly multicultural society.

Summary: The implementation of race-conscious affirmative action results in diversity in medicine. Such diversity has shown increased medical practice in underserved areas, thereby providing better health care for the American people.

\section{Background}

"Mend it, but don't end it."

\section{President William Jefferson Clinton [1]}

America's extremely discriminatory past fostered the exclusive practice of medicine by white men. Women and members of minority groups and lower socioeconomic classes were barred or hindered from attaining the dignified and prestigious medical degree (MD). In the nineteenth century, new medical schools were developed to accommodate women and minorities, particularly African Americans, and dubious private schools emerged lacking university affiliation, called "proprietary schools". The Carnegie Foundation in conjunction with the American Medical Association (AMA) Council on Medical Education hired former schoolmaster Abraham Flexner to report the proper and actual basis of American and Canadian medical instruction for immediate action. In 1910, the Carnegie Foundation published Flexner's accounts titled Medical Education in the United States and Canada: A Report to the Carnegie Foundation for the Advancement 
of Training popularly called the Flexner Report [2]. In it, Flexner summarized in a prominent and sharp approach the 168 medical schools he visited. He called for the closure of all three medical schools that catered entirely to women. He subsequently advocated the reduction of the seven African American medical schools to two, for he felt that "medical care to the [African American] race should never be wholly left to [African American] physicians" [2]. However, he also urged for medical schooling to teach science and technology and stressed medical science application in disease treatment. This powerful report forced medical schools to convert to a more scientific structure and have university affiliation, or otherwise be disqualified from medical licensure and eventually become nonexistent. These changes added prestige to the MD degree [3].

Only in recent times have the diversity trends dramatically changed via the implementation of affirmative action programs. Parallel to the success of affirmative action in achieving diversity in higher education [4], such programs have been under legal and moral attack, particularly against courses that attempt to diversify the cultural climate of educational institutions including medical schools. In July 2003, the Supreme Court of the United States made a momentous decision on affirmative action policy to uphold its use with the exception of quota plans [5]. The decision will have an effect on virtually every facet of American society. The consequences of this judgment will dramatically affect the progression of our esteemed medical workforce and society as a whole.

The need for diversification in medicine is fundamental to the health of the U.S. medical system. The aim of this paper is to convey the consequences of affirmative action implementation: primarily that it achieves diversity more so than race-blind policies. This paper first familiarizes you with the general medical student selection process and then in respect to affirmative action policy, both raceconscious and not. Examining alternatives to race-conscious preference in undergraduate medical school admissions, such as race-blind policies percentage plans and class-based preference, this paper reveals their associated underlying and palpable failures. Furthermore, this paper discusses how race-conscious affirmative action programs achieve diversity yielding more universal health care, in large part in underserved areas often minority occupied; sustain the progression of biomedical advancements through systemic research; bridge the language and cultural gaps that prevent individuals from seeking medical attention; and inhibit discrimination while promoting tolerance within medical student bodies. A brief legal history and analysis of affirmative action implementation is included primarily to supplement the prior information and offer an additional dimension of analysis.

\section{Discussion \\ Medical School Selection Factors}

Medical schools have the societal responsibility to select and instruct the physician workforce of the future. Since medicine is one of the greatest resources for America, this obligation inherently becomes an arduous task that involves screening medical school applicants extensively and carefully selecting candidates for admission who will serve society best. Not only is there a need to train medical students in all medical areas such as neurosurgery, internal medicine, pediatrics, oncology, and emergency medicine; but also the need for competent medical care for all citizens. The Association of American Medical Colleges (AAMC) as a representative of America's 125 medical schools has a duty to help advance these goals.

The future physician workforce is significantly dependent on the caliber of students admitted into accredited U.S. medical schools. The criterion used to select medical students generally includes academic ability, work experience, extra-curricular activities and interests, personality, motivation, and communication skills. In addition to the traditional "standard" selection factors, race must be taken into consideration to sustain a diverse student body. Such diversity will create a physician workforce more favored to practice in underserved areas and ultimately create "culturally competent" medical doctors. With raceconscious affirmative actions programs, underrepresented minority students (classified by the AAMC as African Americans, Hispanics, Native Americans, and mainland Puerto Ricans) gain preference in the admissions process to create a balanced class that shapes the future of the medical profession. (The term "underrepresented minority" recognized the historical barring of such ethnicities from entering the medical profession by deliberate discriminatory practices.)

Students cannot be selected solely on academic qualifications, for instance, on the basis of Grade Point Averages (GPA) and Medical College Admissions Test (MCAT) scores. As statistical analyses have shown, GPA and MCAT scores are good (though not perfect) predictors for passing Step 1 of the United States Medical Licensing Examination (USMLE) [6,7], a required examination for students to progress to the clinical rotation portion of their undergraduate medical studies. However, GPA and MCAT scores are not great predictors of achievements in medical training and success in practicing medicine [8]. There is no evidence to attribute high undergraduate GPAs or MCAT scores to exceptional academic performance during medical school or more importantly to a great level of quality health care a student ultimately provides as a practitioner. But, when combined with the other selection factors, the predictability is dramatically increased. There are "non-cognitive" qualities physicians posses that make 
them "great doctors". These characteristics are measures of competency and compassion, for example, the overall commitment to serve society's medically needy, integrity, truthfulness, and determination. Such admired attributes cannot be adequately assessed by GPA or MCAT performance [9]. Personal statements have been extensively used to evaluate applicant communications abilities, although hardships and obstacles encountered by applicants are often expressed in these documents and considered by evaluators in the admissions process.

Race-conscious programs allow for the factoring of societal or group-based adversity into medical school admission selection process. In addition, there is a pronounced need for diversification in the health care industry to meet the needs of underserved populations, to be more representative of increasing multiculturalism, and to accelerate the progress of biomedical research. There are an abundance of medical disparities on the basis of race and ethnicity that affect society as a whole. By continuing to implementing race-conscious affirmative action programs, these disparities will also continue to decrease [10].

\section{Race-Blind Admissions Policy and Inherent Flaws}

Opponents of affirmative action argue that medical students should be selected without regard or even knowledge of their race or ethnicity. Such race-blind policy would give rise to a massive shift similar to the pre-civil rights age when segregation dominated. Cohen [11] performed a study that analyzed the 119 non-minority medical schools' admission data for 2001. He applied a known and accepted algorithm used on law-school admissions [12]. The algorithm mimicked a "numbers only" or admissions test based policy to measure the effects of abandoning race as a factor in law school admissions decisions. Cohen concluded that $70 \%$ fewer applicants would have been accepted under the scenario devoid of affirmative action. This would leave only $3 \%$ of all medical students with underrepresented minority status. Such a scenario will defeat the tremendous progress of diversification in medicine that the nation has laboriously strived to achieve.

Disadvantages in early education contribute to minorities' low test scores. Many educators believe a host of interconnected factors are responsible for such a disadvantage including poorly equipped schools (i.e. computers, activities, after school programs, test preparation), fewer competent instructors, stereotypically lowered expectations of teachers of minority students and minority students themselves, and the lack of domestic and social support [11]. Although low income level is an additional factor, minority students from middle-class families have been shown to have lower academic achievement as a meas- ured by GPA and SAT scores than whites and Asians $[13,14]$. Such evidence of disparity between minority and non-minority groups reveal the immense social, educational, cultural, and economic forces still operating along racial lines in this country.

Legal restrictions on the use of affirmation action have created a public opinion that such programs are not necessary to reach diversity. Though such expectations are have decreased since the U.S. Supreme Court has held affirmative action constitutional [5], they have led to proposals of various non-race based policy to render the same or similar effects of affirmative action implementation (particularly, diversification). Seemingly attractive programs built on the basis of alternative markers, for instance, low-income area zip-codes, surmounting adversity, and disadvantaged family conditions $[15,16]$, are forms of the affirmative action that attempt to achieve racial and ethnic diversity but bypass the use of race.

\section{Percentage Plans}

Mainly as a response in states that have banned affirmative action programs, there has been a surge in the use of percentage plans in which fixed percentages of a high school's top graduates are guaranteed acceptance to a state institution of higher learning. As an alternative to affirmative action policy, percentage plans are simply a failing concept without simultaneous affirmative action programs for undergraduate admissions. The U.S. Commission on Civil Rights [17] comprehensively examined the use of such programs in California, Texas, and Florida undergraduate schools and found no improvement in diversity, and, in some cases, a decrease in African American and Hispanic enrollment. With respect to medical school admissions (and other graduate and professional programs), this policy simply cannot work. Firstly, undergraduate schools are not adequately diverse, secondly, percentage plans are not increasing diversity and, thirdly, the top graduating class does not necessarily represent the best physicians for the America's future healthcare workforce. Furthermore, the legal standing of percentage plans is being challenged on the same grounds as those used against affirmative action as well as unique claims of illegality $[11,18]$.

\section{Class-Based Preference}

The use of socioeconomic class preference in the medical school admissions is appealing on the surface because it would drastically lower the resentment stimulated by race-conscious affirmative action and would achieve a portion of the goals of race-conscious affirmative action implementation, for underrepresented minority applicants have significantly lower mean family incomes [19]. However, the two prevailing cons to class-based affirmative action are that the basis of affirmative action execu- 
tion was to interrupt the racial and ethnic discrimination and segregation, regardless of class, and, as mentioned previously, minority students from middle-class families have been shown to have greater academic disadvantage as measured by GPA and SAT scores than whites and Asians $[13,14]$. These disadvantages are not attributed to genetic factors [19-21], but are influenced by the early and consistent inequalities encountered in the educational field from kindergarten to higher education [22].

\section{Affirmative Action Minimizes Medical Disparities Minority Practice in Underserved Areas}

Collectively, diversity in medical education provides enhanced access to health care for underserved populations. Many studies provide evidence that minority physicians are more likely than their non-minority colleagues to practice in underserved and often minority populations $[4,10,23,24]$. Despite the same insurance, income, and medical conditions, a congressionally commissioned report of the National Institutes of Medicine (NIH) [25] suggests that minorities are often left with fewer diagnostic tests, less sophisticated treatments, and ultimately inferior care. These intolerable racial disparities in medicine can be diminished by diversity of medical practitioners who treat underrepresented minorities, in addition to financial incentives for those who practice in such environments. Minority physicians are more likely to enter primary care specialties, work in underserved and disadvantaged areas, and provide health care to the medically indigent, irrespective of a patient's race or ethnicity, thereby reducing the racial and ethnic health disparities [10].

\section{Biomedical Research Promoted by Minorities}

Congress has identified various medical disparities generally on the basis of race that plague our health care system and also acknowledge the contributions of minority medical professionals in combating them. Congress is eliminating the inequalities by allocating scholarship funds and creating programs aimed at disadvantaged and minority individuals in medical and scientific professions (i.e. the Minority Biomedical Research Support Program, one of the largest of its kind instituted by the NIH to increase minority researchers in the field of biomedical sciences). The NIH has even recognized that the momentum of the scientific progression depends upon diverse biomedical investigators [26].

The American research agenda is primarily promoted and investigated by individuals who feel and see the problems they wish to solve. Diversifying the medical (MD) and doctoral (PhD) student pool will only broaden the research foundation of our country, especially areas of public health, biosocial, and medical concerns. Such a workforce will be equipped with the tools necessary to combat the various ailments our country faces, including racial discrimination.

\section{Minority Patient Satisfaction}

Studies indicate that minority patients have greater unwillingness to accept physician recommendations or seek medical care than their white counterparts [25]. This predilection may be due to language and cultural barriers [27]; however, in the case of African Americans, a NIH study [25] states that racial preference in their providers may be attributed to the general disbelief in medical professionals that results from racial discrimination and segregated, and ultimately substandard, care for minorities. Though racial preference exists in minority populations for their medical providers, the notion that patients should always have physicians of their own race or that minority medical doctors can only deliver great care to minority patients is foolish. On the contrary, cultural competency should be promoted among all physicians. Consumer choice, especially when it leads to greater patient satisfaction and improved health care, is another reason for diversity and race-conscious programs in medical school admissions.

\section{Classroom Diversity Is Favored}

Medical students at Harvard University and the University of California, San Francisco have shown support for affirmative action in admissions as measured by survey [28]. The students expressed that racial diversity enhances their medical education experience, ultimately improving their ability in practicing in an increasing multicultural society and patient body. In addition, the study shows that exposure to diversity contributes to greater tolerance and less discrimination and the ability to comprehend multiple perspectives. A textbook alone cannot adequately teach these vital principles to our physician workforce. Adequate representation among students and faculty is the only real option to successfully integrate such education into the medical school experience and produce "culturally competent" physicians. Also, as previously mentioned, racial preference of minority patients is likely due to language and cultural barriers, and classroom diversity will assistant in bridging the minority patient and physician relationship, irrespective of race or ethnicity, thereby shrinking medical disparities.

\section{History and Legal Context of Affirmative Action}

The United State Constitution is by far not a color-blind document. Members of Congress were required to be "citizens" for numerous years and the President was required to be a natural born citizen or a citizen at the time of the Constitution's adoption. However, such seemingly fair requirements failed to include anyone other than whites, especially African Americans. The U.S. Supreme Court eventually expanded citizenship, first offering it to freed 
slaves slightly breaking the color-barrier. The birth of affirmative action began with the Fourteenth Amendment. The Equal Protection Clause of the Fourteenth Amendment provides that "No State shall ... deny to any person ... the equal protection of the law" [29]. Justice Black noted that the Amendment was to protect African Americans from discrimination, particularly ex-slaves [30].

In 1963, President Kennedy introduced the term "affirmative action" in Executive Order 10,925, an order that stated discrimination on the basis of race, creed, color, or ethnicity was forbidden [31]. The Civil Rights Act of 1964 broadened the scope of protection to private employers and educational establishments who receive federal funding [32]. In 1965, President Lyndon Johnson expanded the extent of affirmative action in Executive Order 11,246 providing equal opportunity in federal employment [33]. Though initially for federal and private employment and educational institutions in receipt of federal aid, affirmative action eventually expanded to higher education admissions programs.

In the 1978 landmark case of The Regents of the University of California v. Bakke [34], the U.S. Supreme Court determined the UC Davis quota-based system was unconstitutional in a strongly divided decision. UC Davis rejected Allen Bakke from medical school admissions twice, though Bakke had higher average GPA and MCAT scores than a number of minority student admitted under a special admissions program. Bakke argued that the special admission policy violated the Equal Protection Clause of the Fourteenth Amendment. UC Davis appealed to the Supreme Court and marked the first time the U.S. Supreme Court considered affirmative action in higher education admissions. Justice Powell shaped a classic transitional decision that said that affirmative action plans pass strict scrutiny (and are constitutional) only when race would be a factor in the admissions process, and not the entire selection factor (i.e. quotas).

The most recent affirmative action case to reach Supreme Court decision was Grutter v. Bollinger [5], expected to impact all of higher education including medical schools. Petitioner Grutter explicitly claimed that the University of Michigan Law School's affirmative action policy violated her constitutional protections. The Supreme Court also accepted a companion case argued April 1 15t, 2003, Gratz v. Bollinger [35], involving undergraduate admissions but with the use of the quota system. Both Grutter and Gratz were denied admission to the University of Michigan Law School and College respectively, claiming they were unfairly rejected because of race-conscious affirmative action policies. But, the undergraduate case involved the university instituting a quota system providing an addi- tional 20 out of a total 100 points to every single underrepresented minority applicant, equating to a full GPA point. As a "friend of the Court," Harvard University, UCLA, AAMC, Howard University, Carnegie Mellon, and many others filed amici curiae briefs in support of affirmative action programs, primarily stating the essential role of diversity in all higher education and society.

In July 2003, the U.S. Supreme Court ruled that the University of Michigan has a constitutional backing to institute race-conscious affirmative action where such preference is a "plus" or supplemental factor. But, the opinion for the undergraduate quota case (Gratz v. Bollinger) re-confirms Justice Powell's opinion in the Bakke case that said race-conscious admissions programs cannot "insulat $[e]$ each category of applicants with certain desired qualifications from competition with all other applicants" [34]. Therefore, any institution cannot constitutionally implement a race-based quota system, but may pursue race-based preference in the admissions process if they have a compelling interest (i.e. to seek diversity).

\section{Conclusion}

Evidently, the use of race-conscious programs by medical schools is currently the only method to successfully meet societal obligations through diversity. Certainly, we would enjoy a time when race is entirely irrelevant and an era where universal health care exists for all areas, eliminating the term "underserved populations" from reports. Similarly, we would enjoy the eradication of medical disparities where diagnosis and treatment depends not on the race or ethnicity of the patient, but the quality of the practicing physician. Though we have yet to see such a time, affirmative action implementation is a positive force moving our entire medical system closer to diversity. Hopefully, the U.S. Supreme Court will acknowledge that the affirmative action system is not entirely perfect but is the optimal choice in achieving the medical goals set forth by the AMA. The Hippocratic Oath medical doctors affirm to now as they did a thousand years ago pledges the competent practice for the "benefit of the sick" [36]. Affirmative action is merely a vehicle to achieve societal goals and notably benefit the patients.

The need for diversification in medicine is absolutely vital to the health of the U.S. medical system. Achieved through race-conscious affirmative action programs, diversity would yield more universal health care, especially in underserved areas often occupied by minority groups. Broadening the range of the medical student pool will sustain the progression of biomedical advancements through systemic research funded by the federal government. Importantly, a result of diversification would be to bridge the language and cultural gaps that prevent people from seeking medical attention, a "consumer choice" 
proposition that America cannot ignore. Furthermore, having a diverse medical student body will promote a sense of tolerance and diminish prejudice in the health care field. By and large, diversity simply promotes better medical practice and health care for Americans.

\section{Competing Interests}

None declared.

\section{Acknowledgements}

I wish to thank Prof. Capuano for fostering a motivating discussion on affirmative action and the need for reflection in all areas of the arts and sciences, although this paper concerns U.S. medicine in particular.

\section{References}

I. Clinton W]: Remarks By William Jefferson Clinton On Affirmative Action. Washington, DC, The White House: Office of the Press Secretary, The National Archives; 1995. July 19

2. Flexner A: Medical Education in the United States and Canada: A Report to the Carnegie Foundation for the Advancement of Training. New York, Carnegie Foundation for the Advancement of Training; Bulletin No. 4; 1910.

3. Hiatt MD and Stockton CG: The Impact of the Flexner Report on the Fate of Medical Schools in North America After 1909. JP\&S 2003, 8:37-40.

4. Keith SN: Effects of Affirmative Action in Medical Schools: A Study of the Class of 1975. N Engl J Med 1985, 313:

5. Barbara Grutter, Petitioner v. Lee Bollinger, et al. Volume No. 02-24I. U.S. Supreme Court; 2003.

6. AAMC: Minority Students in Medical Education: Facts and Figures, Volumes VII-XII. Washington, DC, Association of American Medical Colleges; 1993-2003

7. Koenig J, Huff $K$ and Julian E: Predictive Validity of the Medical College Admission Test. Washington, DC, Association of American Medical Colleges; 2002.

8. Ferguson $E$, James $D$ and Madeley L: Factors associated with success in medical school: systematic review of the literature. $B$ Med J 2002, 324:952-957.

9. Tracey TJ and Sedlacek WE: Noncognitive variables in predicting academic success by race. Measurement and Evaluation in Counseling and Development 1984, 16:171-178.

10. Kington $R$, Tisnado D and Carlisle DM: Increasing racial and ethnic diversity among physicians: an intervention to address health disparities? The Right Thing To Do, The Smart Thing To Do: Enhancing Diversity in the Health Professions. Edited by: Smedley B D, Colburn L and Evans C H. Washington, DC, National Academy Press; $200 \mathrm{I}$.

II. Cohen JJ: The Consequences of Premature Abandonment of Affirmative Action in Medical School Admissions. JAMA 2003, 289: I |43-I I49.

12. Wightman LF: The threat to diversify in legal education: an empirical analysis of the consequences of abandoning race as a factor in law school admissions decision. New York Univ Law $\operatorname{Rev}$ 1997, 72: I-3.

13. Steele CM: $\mathbf{A}$ threat in the air - how stereotypes shape intellectual identity and performance. Am Psychol I997, 52:6 |3-629.

14. Jencks $C$ and Phillips M: The Black-White Test. Washington, D.C., Brookings Institution; 1998.

15. Ruddenstine NL: Student diversity and higher learning. Diversity Challenged: Evidence on the Impact of Affirmative Action. Edited by: Orfield $G$ and Kurlander M. Boston, MA, Harvard Education Press; 200I.

16. Orfield G: Campus resegregation and its alternatives. Chilling Admissions: the Affirmative Action Crisis and the Search for Alternatives. Edited by: Orfield $G$ and Miller E. Boston, MA, Harvard Education Press; 2001.

17. USCCR: Beyond Percentage Plans: The Challenge of Equal Opportunity in Higher Education. Washington, DC, U.S. Commission on Civil Rights; 2002

18. Perez T: Current legal status of affirmative action in higher education. The Right Thing To Do, The Smart Thing To Do: Enhancing Diversity in the Health Professions. Edited by: Smedley B D, Colburn L and Evans C H. Washington, DC, National Academy Press; 2001.
19. Nickens Herbert W. and Cohen Jordan J.: On Affirmative Action. JAMA 1996, 275:572-574

20. Fraser S: The Bell Curve Wars: Race, Intelligence, and The Future of America. New York, NY, Basic Books; 1995.

21. Herrstein RJ: The Bell Curve: Intelligence and Class Structure in American Life. New York, NY, Free Press; 1994.

22. Nickens HW and Ready T: Problems in the pipeline. More Minorities in Health. Edited by: Burroughs H C and Kehrer B H. Menlo Park, CA, Henry J. Kaiser Family Foundation; 1994: I-29.

23. Cantor JC, Miles EL, Baker LC and Barker DC: Physician service to the uninsured: implication for affirmative action in medical education. Inquiry 1996, 33:167-180.

24. Komaromy M, Grumbach K and Drake M: The Role of Black and Hispanic Physicians in Providing Health Care for Underserved Populations. N Engl J Med 1996, 4: I305-1310.

25. Brian S, Adrienne SY and Nelson A: Unequal Treatment: Confronting Racial \& Ethnic Disparities in Health. Washington, DC, National Academy Press; 2002.

26. NIH: Strategic Plan on Reducing Health Disparities. Washington D.C., Warren G. Magnuson Clinical Center; 2002.

27. Saha S: Patient-Physician Racial Concordance and the Perceived Quality and Use of Health Care. Arch Intern Med 1999.

28. Whitla D: Educational Benefits of Diversity in Medical School. Acad Med 2003.

29. Equal Protection Clause. US Const Amend XIV s. I 1866

30. Goldberg v. Kelly. Volume 397 U.S. 254. U.S. Supreme Court; 1970.

31. Executive Order No. 10,925. 3 C.F.R. 448 . 1959-1963

32. Civil Rights Act. U.S.C 1965, 42: 2000d:

33. Executive Order No. I I,246. 3 C.F.R. 339 . 1964-1965

34. The Regents of the University of California v. Bakke. U.S. Supreme Court 1978, No. 78I I, 438 U.S. 265:

35. Barbara Grutter, Petitioner v. Lee Bollinger, et al. Volume No. 02-24I. U.S. Supreme Court; 2003

36. Jennifer Gratz and Patrick Hamacher, Petitioners v. Lee Bollinger, et al. U.S. Supreme Court; 2002.

37. Tan SY: Medicine in Stamps. Hippocrates: Father of Medicine. Singapore Med J 2002, 43:5-6.

\section{Pre-publication history}

The pre-publication history for this paper can be accessed here:

\section{http://www.biomedcentral.com/1472-6920/3/6/prepub}

Publish with Bio Med Central and every scientist can read your work free of charge

"BioMed Central will be the most significant development for disseminating the results of biomedical research in our lifetime. "

Sir Paul Nurse, Cancer Research UK

Your research papers will be:

- available free of charge to the entire biomedical community

- peer reviewed and published immediately upon acceptance

- cited in PubMed and archived on PubMed Central

- yours - you keep the copyright 